\title{
IMPLEMENTASI SUPERVISI PENGAWAS \\ PENDIDIKAN AGAMA ISLAM UNTUK MENINGKATKAN KOMPETENSI \\ GURU PENDIDIKAN AGAMA ISLAM SEKOLAH DASAR \\ DI PONDOK KELAPA BENGKULU TENGAH \\ SEMESTER I TAHUN AJARAN 2016/2017
}

\section{ELISMARWATI}

\begin{abstract}
This study aims to determine: 1) the implementation of academic supervision of supervisors to improve the competence of Islamic Elementary School Education teachers in Pondok Kelapa Bengkulu Tengah, 2) obstacles faced by supervisors in supervising Islamic Education, 3) solutions so that supervisory supervision can improve the competence of PAI SD teachers in Pondok Kelapa Bengkulu Tengah. The results of the study show that: 1) supervision that has been carried out by supervisors to Islamic Education teachers is quite effective in increasing the competency of PAI teachers as seen from the teacher's mastery of learning theory and learning principles, teacher effectiveness in educating learning, and facilitating the development of potential students. 2) Obstacles experienced by supervisors in supervision are not ideal between assisted teachers and the number of supervisors, lack of motivation for PAI teachers to innovate learning in the use of ICT so learning is not effective, 3) Solution to constraints is new supervisor recruitment, increased intensity of supervision of classroom visits and improvement supervisory supervision program periodically and continuously.
\end{abstract}

Kata Kunci: Implementasi supervisi pengawas PAI, Kompetensi Guru PAI.

\section{A. PENDAhuluan}

Mutu Sumber Daya Manusia berhubungan erat dengan mutu pendidikan. Mutu pendidikan sering diindikasikan dengan kondisi yang baik dan memenuhi syarat dalam segala komponen pendidikan yang meliputi masukan, proses, tenaga kependidikan, sarana prasarana dan biaya.

Dalam proses pendidikan, pengawasan atau supervisi adalah bagian tidak terpisahkan dalam upaya peningkatan prestasi belajar serta mutu sekolah. Menurut Sahertian (2008: 19) bahwa pengawasan 
atau supervisi pendidikan merupakan usaha memberikan layanan kepada stakeholder pendidikan, terutama kepada guru-guru, baik secara individu maupun secara kelompok dalam usaha memperbaiki kualitas proses dan hasil pembelajaran. Sedangkan menurut Sagala (2010: 95) memperjelas hakikat pengawasan pendidikan pada substansinya, dimana Substansi hakikat pengawasan adalah menunjuk pada segenap upaya bantuan supervisor kepada stakeholder pendidikan terutama guru terhadap perbaikan-perbaikan dan pembinaan aspekpembelajaran.

Tenaga kependidikan yang profesional adalah tenaga kependidikan yang mampu membelajarkan siswa secara efektif dan efesien sesuai dengan kendala sumber daya dan lingkungan. Minat, bakat, kemampuan, dan potensi peserta didik tidak akan berkembang secara optimal tanpa bantuan guru. Banyak guru yang mengalami kesulitan dalam aspek-aspek teknis metodologis sehingga bahan ajar kurang dipahami peserta didik. Kesulitan-kesulitan yang dialami guru senantiasa dipecahkan bersama, baik melalui Kelompok Kerja Guru (KKG) maupun komunikasi yang efektif dengan Pengawas Pendidikan Agama Islam.

Pembinaan merupakan upaya peningkatan profesionalisme guru yang dapat dilakukan melalui kegiatan seminar, pelatihan, dan pendidikan rangka pembinaan profesi dan karier. Pembinaan profesi guru meliputi pembinaan kompetensi pedagogik, kompetensi kepribadian, kompetensi profesional, dan kompetensi sosial. Pembinaan karir sebagaimana aktivitas pengembangan profesi guru bersifat terus-menerus, serta menjalani proses pengembangan profesional berkelanjutan (PPB) yang tersedia untuk mendukung pengembangan kompetensi guru, kepala sekolah, dan pengawas sekolah. Dalam konteks interaksi kepengawasan sekolah atau 
kepengawasan pembelajaran merupakan sentral utama pembinaan adalah guru.

Pengawas sekolah memegang peran penting dalam mendukung ketercapaian pendidikan, karena pengawas melaksanakan penilaian dan pembinaan sesuai fungsi supervisi. Supervisi yang dilakukan secara akademik maupun supervisi manajerial. Tugas lain pengawas melakukan evaluasi dan monitoring pelaksanaan program sekolah dan pengembangannya secara kolaboratif dengan stakeholder sekolah.

Dalam PP No. 19 Tahun 2005 tentang standar mutu pendidikan, dimana peranan pengawas satuan pendidikan/sekolah sangat penting dalam meningkatkan mutu pendidikan pada satuan pendidikan binaannya. Oleh sebab itu, pembinaan pengawas agar dapat melaksanakan tugas kepengawasan akademik mutlak diperlukan. Upaya-upaya yang perlu dilakukan Pengawas Pendidikan Agama Islam guna menjadikan pendidikan formal persekolahan menjadi motor dan agen perubahan yang dapat memberi dampak pada semua jalur pendidikan dan seluruh pemangku kepentingan pendidikan dan penanaman akhlakul karimah.

Berdasarkan fakta di lapangan bahwa dalam pelaksanaan supervisi yang dilakukan oleh pengawas terhadap guru Pendidikan Agama Islam belum maksimal dalam melaksanakan tugasnya. Meskipun dalam rancangan secara teoritik sudah ada pihak yang diharapkan dapat melaksanakan supervisi terhadap guru Pendidikan Agama Islam yaitu pengawas sekolah, namun kepengawasan belum terlaksana secara efektif, dimana pengawas datang ke sekolah mengadakan supervisi dan monitoring hanya sebatas meminta data administrasi sekolah itupun pada waktu-waktu tertentu dan tidak diikuti dengan tindak lanjut, serta tidak optimalnya dalam 
melaksanakan kunjungan kelas. hal ini diakibatkan pengawas Pendidikan agama Islam karena purnanya masa kerja atau dipromosikan ke jabatan yang lain ( Pengawas PAI), kegiatan KKG masih minim dilaksanakan. Dengan demikian berarti pelaksanaan terhadap peningkatan kompetensi guru Pendidkan Agama Islam sebagai upaya peningkatan mutu Pendidikan Agama Islam dalam pelaksanaan proses pembelajaran di sekolah juga belum optimal.

\section{B. Pembahasan}

Pengawas guru Pendidikan Agama Islam Sekolah Dasar di Pondok Kelapa Bengkulu Tengah berjumlah 1 (satu) orang mempunyai tugas dan tanggung jawab kepengawasan terhadap guru Pendidikan Agama Islam di seluruh sekolah umum terdiri dari: 18 SDN, 6 SMPN, 1SMAN, 1 SMK, 9 TK, dan 1 MI. Dengan jumlah 36 sekolah dan 65 orang guru, namun dalam penelitian ini hanya menilai kompetensi guru Pendidikan Agama Islam Sekolah Dasar.

Pengawas sebagai bagian dari satuan pendidikan yang mengawasi tugas dan tanggung jawab terhadap guru Pendidikan Agama Islam dalam menilai dan membina penyelenggaraan pendidikan pada sejumlah satuan pendidikan/sekolah, untuk menentukan derajat kualitas berdasarkan kriteria yang ditetapkan dalam penyelenggaraan pendidikan di sekolah, dalam hal ini berkaitan dengan kompetensi guru. Oleh karena itu kompetensi penting diperhatikan oleh pengawas Pendidikan Agama Islam dan perlu disupervisi.

Bentuk supervisi pengawas Pendidikan Agama Islam yang telah dilaksananakan untuk meningkatkan kompetensi guru Pendidikan Agama Islam Sekolah Dasar antara lain: 1)penguasaan karakteristik 
guru terhadap peserta didik, 2)penguasaan guru terhadap teori belajar dan prinsip pembelajaran, kreativitas guru dalam pengembangan kurikulum, 3)efektivitas guru dalam pembelajaran yang mendidik, 4)pemanfaatan TIK untuk pembelajaran yang efektif, 5)fasilitasi pengembangan potensi peserta didik, 6)komunikasi guru dengan peserta didik, 7)penyelenggaraan penilaian dan evaluasi proses dan hasil belajar, 8)pemanfaatan hasil penilaian dan evaluasi untuk kepentingan pembelajaran, 9) kegiatan reflektif untuk peningkatan kualitas pembelajaran, dengan rincian:

1. Penguasaan karakteristik guru terhadap peserta didik

Supervisi pengawas dalam meningkatkan penguasaan karakteristik guru terhadap peserta didik antara lain memberikan arahan mengenai karakteristik peserta didik. Guru harus mampu menguasai karakteristik peserta didiknya agar dapat menyesuaikan metode pengajaran sehingga peserta didik mampu menguasai materi yang diberikan.

Pengawas membimbing Guru Pendidikan Agama Islam dalam mengidentifikasi potensi peserta didik sesuai dengan kemampuan awalnya dan memberikan layanan sesuai dengan bakat dan minatnya. Kemampuan awal peserta didik diarahkan agar berkembang dengan pembelajaran yang menarik ditambah dengan kegiatan ekstra kurikuler agar dapat menguasai materi Pendidikan Agama Islam, salah satunya dengan Program Tuntas Baca Tulis Al-Qur'an (TBTQ). 
2. Penguasaan guru terhadap teori belajar dan prinsip pembelajaran Supervisi yang telah dilakukan pengawas Pendidikan Agama Islam terhadap guru Pendidikan Agama Islam Sekolah Dasar mengenai kemampuan menguasai teori belajar dan prinsipprinsip pembelajaran. Dimana hasil belajar peserta didik diarahkan oleh guru PAI seimbang pada tiga ranah, yaitu cognitive domain yang berkaitan dengan pengetahuan hapalan dan pengembangan intelektual, affective domain, yang berkaitan dengan minat, sikap dan nilai serta pengembangan apresiasi dan penyesuaian, psychomotordomain,yang berkaitan dengan prilaku yang menuntut koordinasi syaraf.

Pengawas memberikan pembinaan terhadap guru Pendidikan Agama Islam tentang teori-teori belajar dan prinsip pembelajaran dalam forum KKG PAI di Pondok Kelapa Bengkulu Tengah. Pengawas menyampaikan tentang beberapa teori belajar, di antaranya Teori Disiplin Mental yang menitikberatkan disiplin dan melatih mental peserta didik dalam pembelajaran, Teori bahaviorisme yang memandang kehidupan individu terdiri atas unsur-unsur seperti halnya molekul-molekul dan Teori cognitive Gestalt-Field antara lain mencakup belajar itu berdasarkan keseluruhan, anak yang belajar merupakan keseluruhan, belajar berkat insight, belajar berdasarkan pengalaman, prinsip aktivitas, prinsip motivasi, prinsip individualitas (perbedaan individu), prinsip lingkungan, prinsip konsentrasi, prinsip kebebasan, prinsip peragaan, pinsip kerjasama dan persaingan, prinsip apersepsi, prinsip korelasi, prinsip efisiensi dan efektifitas, prinsip globalitas, serta prinsip permainan dan hiburan. 
Pengawas Pendidikan Agama Islam dalam pembinaannya mengarahkan agar guru Pendidikan Agama Islam dapat memahami prinsip pembelajaran bahwa manusia dalam batasbatas kemampuan fisiknya dapat dibentuk melalui cara-cara yang terbatas. Hal ini sesuai dengan pendapat bahwa jiwa itu bagaikan meja lilin (tabularasa) yang bersih dari goresan. Pengalamanlah yang membentuk kepribadiannnya.

3. Kreativitas guru dalam pengembangan kurikulum pelajaran, metode dan strategi, serta evaluasi yang meliputi aspek sikap, pengetahuan, dan ketrampilan.

4. Efektivitas guru dalam pembelajaran yang mendidik. Guru mengajar sesuai dengan substansi materi ajar yang harus dikuasai dan diajarkan dengan interaktif, menyenangkan, dan memberikan ruang prakarsa, kemandirian dan kreativitas peserta didik.

5. Pemanfaatan TIK untuk pembelajaran yang efektif. Guru Pendidikan Agama Islam mengikuti pelatihan dan pemanfaatan media pembelajaran yang kemudian diimplentasikan di sekolah dalam pembelajaran.

6. Fasilitasi pengembangan potensi peserta didik. Guru Pendidikan Agama Islam mengajar dengan menciptakan suasana pembelajaran yang dapat dinikmati peserta didik, memberikan keleluasaan dalam meyampaikan gagasan dan ide yang kreatif, serta pengembangan potensi melalui kegiatan ekstra kurikuler.

7. Komunikasi guru dengan peserta didik. Guru Pendidikan Agama Islam memberikan layanan dalam pendampingan kegiatan belajar serta memberi perhatian dan solusi atas permasalahan yang berhubungan dengan peserta didik. 
8. Penyelenggaraan penilaian dan evaluasi proses dan hasil belajar. Penilaian Pendidikan Agama Islam dilaksanakan sesuai dengan prosedur, cakupan mata pelajaran, dan meliputi penilaian sikap. Pengetahuan, dan ketrampilan.

9. Pemanfaatan hasil penilaian dan evaluasi untuk kepentingan pembelajaran. Guru Pendidikan Agama islam menganalisis hasil evaluasi pembelajaran dan merancang tindak lanjut yang meliputi perbaikan dan pengayaan materi bagi peserta didik.

10. Kegiatan reflektif untuk peningkatan kualitas pembelajaran. Guru melaksanakan kegiatan penilaian efektivitas pembelajaran dengan menghubungkan antara program, proses, dan evaluasi pembelajaran.

Hal ini menunjukkan Implementasi supervisi yang telah dilaksanakan oleh pengawas Pendidikan Agama Islam terhadap guru Pendidikan Agama Islam Sekolah Dasar untuk meningkatkan kompetensi di Pondok Kelapa Bengkulu Tengah Semester 1 Tahun Ajaran 2016/2017 dan berhasil baik.

Kendala pengawas Pendidikan Agama Islam di Pondok Kelapa adalah jumlah sekolah binaan yang terlalu banyak, intensitas supervisi kelas yang belum optimal, pengembangan kompetensi supervisi pengawas Pendidikan Agama Islam terhadap kompetensi guru Pendidikan Agama Islam Sekolah Dasar terutama pembelajaran yang bersifat TIK

Solusi yang dilakukan agar pelaksanaan supervisi pengawas Pendidikan Agama Islam dapat lebih efektif dalam meningkatkan kompetensi guru Pendidikan Agama Islam, rekrutmen dan pengangkatan pengawas Pendidikan Agama Islam yang baru oleh Kementerian Agama perlu di pertimbangkan, 
penambahan intensitas supervisi Pengawas Pendidikan Agama Islam, meningkatkan pembinaan terhadap pengawas melalui monitoring dan evaluasi terhadap perencanaan dan pelaksanaan program yang dilakukan pengawas secara berkala dan berkesinambungan.

\section{KESIMPULAN}

1. Jumlah pengawas Pendidikan Agama Islam ideal akan berpengaruh positif terhadap kinerja kepengawasan. Jumlah pengawas Pendidikan Agama Islam disesuaikan dengan jumlah guru Pendidikan Agama Islam dan sekolah yang menjadi sasaran binaan.

2. Pengawas Pendidikan Agama Islam mempunyai tugas mengawasi, memantau, menasehati, mengkoordinasi, dan melaporkan hasil kepengawasan guru Pendidikan Agama Islam agar program kepengawasan berjalan secara efektif.

3. Kerjasama antara pengawas Pendidikan Agama Islam di Kemenag dengan pengawas TK, SD, SMP,dan SMA/K di Diknas, kepala Sekolah dan pengurus kegiatan KKGPAI perlu dalam meningkatkan kompetensi guru Pendidikan Agama Islam sehingga dapat meningkatkan mutu Pendidikan Agama Islam sekolah Dasar

4. Data yang diperoleh dari supervisi harus dijadikan dasar dalam menetapkan aspek-aspek yang perlu dikembangkan dan strategi peningkatan kualitas guru Pendidikan Agama Islam.

5. Supervisi yang efektif akan mempengaruhi dalam peningkatan kompetensi guru Pendidikan Agama Islam 
Penulis : Dra. Elismarwati, M.Pd.I adalah Pengawas Kementerian Agama Kabupaten Bengkulu Tengah

\section{DAFTAR PUSTAKA}

Asma, N. 2006. Model Pembelajaran Kooperatif. Jakarta: Depdiknas.

Arikunto, Suharsimi (2004). Dasar-dasar Supervisi. Jakarta: Penerbit Rineka Cipta

Masaong, Abd. Kadim (2012) . Supervisi Pembelajaran dan PengembanganKapasitas Guru. Bandung: Penerbit Alfabeta

Milles, Matthew B, dkk (2009). Analisis Data Kualitatif. Jakarta: Penerbit Universitas Indonesia (UI-Press)

Moleong, Lexy (2000) Metodologi Penelitian Kualitatif. Bandung: Penerbit PT Remaja Rosdakarya

Purwanto, Ngalim (2010). Administrasi dan Supervisi Pendidikan. Bandung: Penerbit PT Remaja Rosdakarya

Rohmat (2012). Pilar Peningkatan Mutu Pendidikan. Yogyakarta: Penerbit Cipta Media Aksara

Sagala, Syaiful (2009). Kemampuan Professional Guru dan Tenaga Kependidikan. Bandung: Alfabeta

Sahertian, Piet (1981). Prinsip dan Teknik Supervisi Pendidikan. Surabaya: Usaha Nasional

Satori, Djam'an (2012). Metodologi Penelitian Kualitatif. Bandung: Penerbit Alfabeta

Sugiyono (2013). Memahami Penelitian Kualitatif. Bandung: Penerbit CV. Alfabeta

Wiles, Jon and Bondi Joseph (1986). Supervision a Guide to Practice SecondEdition. Columbus: Charles E. Merill Publishing Company 